\title{
COMPLETE MOMENT CONVERGENCE FOR ARRAYS OF ROWWISE EXTENDED NEGATIVELY DEPENDENT RANDOM VARIABLES
}

\author{
Yi Wu, YANG Ding, Xuejun Wang AND WeiYAng Chen
}

\begin{abstract}
In this paper, a general result on complete moment convergence for arrays of rowwise extended negatively dependent (END, in short) random variables is established. As applications, we obtain some results on complete moment convergence for weighted sums of END random variables. The results obtained in the paper generalize and improve some corresponding ones for negatively dependent random variables.
\end{abstract}

Mathematics subject classification (2010): 60F15.

Keywords and phrases: Complete convergence, complete moment convergence, extended negatively dependent random variables.

\section{REFERENCES}

[1] P. L. Hsu, And H. RobBins, Complete convergence and the law of large numbers, Proceedings of the National Academy of Sciences, 33, 25-31, 1947.

[2] Y. S. CHOw, On the rate of moment complete convergence of sample sums and extremes, Bulletin of the Institute of Mathematics Academia Sinica, 16 (3), 177-201, 1988.

[3] L. Liu, Precise large deviations for dependent random variables with heavy tails, Statistics and Probability Letters, 79, 1290-1298, 2009.

[4] E. Lehmann, Some concepts of dependence, The Annals of Mathematical Statistics, 37, 1137-1153, 1966.

[5] K. Joag-Dev, F. Proschan, Negative association of random variables with applications, The Annals of Statistics, 11, 286-295, 1983.

[6] L. LiU, Necessary and sufficient conditions for moderate deviations of dependent random variables with heavy tails, Science in China Series A: Mathematics, 53 (6), 1421-1434, 2010.

[7] Y. Chen, A. Chen, K. W. NG, The strong law of large numbers for extend negatively dependent random variables, Journal of Applied Probability, 47, 908-922, 2010.

[8] A. T. SHEN, Probability inequalities for END sequence and their applications, Journal of Inequalities and Applications, Volume 2011, Article ID 98, 12 pages, 2011.

[9] A. T. SHEN, Bernstein-type inequality for widely dependent sequence and its application to nonparametric regression models, Abstract and Applied Analysis, Volume 2013, Article ID 862602, 9 pages, 2013.

[10] S. J. WANG, W. S. WANG, Extended precise large deviations of random sums in the presence of END structure and consistent variation, Journal of Applied Mathematics, Volume 2012, Article ID 436531, 12 pages, 2012.

[11] Y. F. WU, M. GUAN, Convergence properties of the partial sums for sequences of END random variables, Journal of the Korean Mathematical Society, 49 (6), 1097-1110, 2012.

[12] S. J. WANG, X. J. WANG, Precise large deviations for random sums of END real-valued random variables with consistent variation, Journal of Mathematical Analysis and Applications, 402, 660667, 2013.

[13] D. H. QiU, P. Y. ChEn, R. G. Antonini, A. Volodin, On the complete convergence for arrays of rowwise extended negatively dependent random variables, Journal of the Korean Mathematical Society, 50 (2), 379-392, 2013. 
[14] X. J. Wang, T. C. Hu, A. Volodin, S. H. Hu, Complete convergence for weighted sums and arrays of rowwise extended negatively dependent random variables, Communications in StatisticsTheory and Methods, 42, 2391-2401, 2013.

[15] X. J. WANG, S. J. WANG, S. H. Hu, J. M. Ling, Y. F. WeI, On complete convergence of weighted sums for arrays of rowwise extended negatively dependent random variables, Stochastics: An International Journal of Probability and Stochastic Processes, 85 (6), 1060-1072, 2013.

[16] X. J. WANG, X. Q. LI, S. H. HU, X. H. WANG, On complete convergence for an extended negatively dependent sequence, Communications in Statistics-Theory and Methods, 43 (14), 2923-2937, 2014.

[17] S. H. Sung, K. BudS aba, A. Volodin, Complete convergence for arrays of negatively dependent random variables, Informatics and its Applications, 6 (4), 95-102, 2012.

[18] Q. Y. Wu, Probability Limit Theory for Mixing Sequences, Science Press, Beijing, 2006.

[19] A. T. SHEN, On the strong convergence rate for weighted sums of arrays of rowwise negatively orthant dependent random variables, RACSAM, 107 (2), 257-271, 2013.

[20] A. T. SHEN, Y. ZHANG, A. Volodin, Applications of the Rosenthal-type inequality for negatively superadditive dependent random variables, Metrika, 78, 295-311, 2015. 